\title{
Promoting a mixed-design model of scientific creativity through digital storytelling - the CCQ model for creativity
}

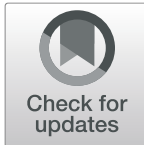

\author{
Zacharoula Smyrnaiou $^{1 *}$ DD, Eleni Georgakopoulou ${ }^{1}$ and Sofoklis Sotiriou ${ }^{2}$
}

\begin{abstract}
Background: This study presents the development of three research tools of scientific creativity. Our aim is to evaluate the development of student creativity while students write digital stories. Three models are linked to create a new model, called Creative, Cognitive, Qualitative Model for Creativity (CCQ tool). Our research tool examines how creativity can be standardized, first by researchers' views and then by teachers and students' creative products. The first tool is based on two existing tools; the Scientific Creativity Structure Model (SCSM) and the TTCT Figural Subscales, and on new characteristics, the effective learning environments, as we have developed them in the CREATIONS Program. We have tried to expand this tool by combining its key elements to the theoretical framework of creativity, as we have approached it in the CREATIONS and the STORIES Programs. The second tool "Students' Creativity Evaluation Model" is a new tool that derives from empirical data and Grounded Theory methods. It examines the expected, original, and innovative ways of students' thinking. The third tool "Experts' Creativity Evaluation Model" allows us to examine the role of experts thinking on writing a story. It aims at tracking experts' model of thinking and is viewed in comparison to the students' creative model of thinking. We create a qualitative tool as we believe that a qualitative method delves deeper into students' internal mechanisms of creativity.

Results: Twelve students' stories from classrooms of different countries which participate to STORIES Program are analyzed indicatively by two independent researchers. The results seem to indicate that digital storytelling increases scientific creativity among students.

Conclusions: The main difference between expert and students' approaches is that experts' stories follow an up to bottom approach, while it is the opposite for students' creative process. It has to be mentioned that almost all of the stories combined science with creative thinking. Students transformed their personal values into stories; therefore, this creative procedure was influenced by social, cultural, and ethnographical characteristics. The contribution of our research is that it offers a research tool that not only measures creativity but also studies the cognitive mechanisms involved in creative thinking.
\end{abstract}

Keywords: Creativity, Digital storytelling, STEM education, Mixed-design research method

\footnotetext{
* Correspondence: zsmyrnaiou@eds.uoa.gr

'School of Philosophy, Department of Educational Studies, National and Kapodistrian University of Athens (NKUA), University Campus, 15784 llissia, Athens, Greece

Full list of author information is available at the end of the article
}

\section{Springer Open}

(c) The Author(s). 2020 Open Access This article is licensed under a Creative Commons Attribution 4.0 International License, which permits use, sharing, adaptation, distribution and reproduction in any medium or format, as long as you give appropriate credit to the original author(s) and the source, provide a link to the Creative Commons licence, and indicate if changes were made. The images or other third party material in this article are included in the article's Creative Commons licence, unless indicated otherwise in a credit line to the material. If material is not included in the article's Creative Commons licence and your intended use is not permitted by statutory regulation or exceeds the permitted use, you will need to obtain permission directly from the copyright holder. To view a copy of this licence, visit http://creativecommons.org/licenses/by/4.0/. 


\section{Introduction}

Nowadays, there is a need to find new ways of scientific thinking. Traditional methods of teaching do not promote scientific literacy, neither do they develop students' motivation to learn. Furthermore, skills and competences play an important role in knowledge acquisition, students' interests, and imagination. These are not taken into consideration when designing school curricula and learning methods, while only few papers have examined the combination of different domains in students' cognitive development. At the same time, Li, Wang, Xiao, and Froyd (2020) suggest that STEM education is not a welldefined field, while STEAM is a new innovative perspective with its own disciplines. Moreover, students have difficulties understanding, representing, and communicating their new concepts. Their prior misconceptions and intuitions are strong, not only due to the context of each notion but also due to the traditional ways of teaching science. As a result, more and more students cannot link what they learn to everyday life. Therefore, creativity is one of the 21st century skills (Holmlund, Lesseig, \& Slavit, 2018), but any attempts to combine creativity in school classrooms often focus on the entertaining side of creativity. Moreover, only few research studies suggest that when students participate in creative procedures, they do not only increase their interest for science education, but they also acquire new knowledge by using different methods of learning. We assume that creative procedures trigger students' internal mechanisms of learning. Therefore, examining the whole procedure that a student follows in order to produce something creative and innovative is of vital significance. At the same time, there are a variety of definitions of creativity in scientific community. Different perceptions of the meaning of creativity have led to a wide variety of techniques to assess creativity. Several research studies combine the creative process, creative product, creative person, and creative environment, and many suggest standardized tests to measure creativity. We believe that creativity is an internal mechanism of the brain that influences other representative systems. Finally, students produce a new learning product, differently expressed but in accordance with scientific knowledge. Little research has been conducted in order to analyze creativity using qualitative methods in an attempt to approach the internal mechanisms of creativity as a part of students' thinking. Therefore, this paper presents a coding scheme to identify scientific creativity in artifacts produced by students and experts. Our main research questions are as follows:

1. How can we evaluate qualitatively students' creative thinking and the whole creative procedure that students participate in?
2. Can the proposed research tools for creativity analyze students' creative skills?

3. Can creative skills lead to students' cognitive development?

4. Can digital storytelling increase student's scientific creativity?

The main aims of this research are to examine if the proposed three research tools that measure creativity can analyze students' creative skills, offering a holistic and deep understanding of creativity and if digital storytelling-especially in prototype context, such as the missions on Mars-can increase students' creativity in a scientifically acceptable way. This research is not only important because it offers a three-dimensional model of creativity but also because it examines qualitatively the internal mechanisms of creativity, and the deeper mental competences students activate to produce creative writing. As a result, we attempt to fill the gap in scientific creativity by not only suggesting a new definition of creativity but also by displaying a qualitative tool in order to realize the way students think when they produce a creative product.

\section{The CREATIONS and STORIES Program}

There are lots of works worldwide to establish a conceptual framework of STEM and STEAM education (Yata, Ohtani, \& Isobe, 2020). In the framework of the European Project CREATIONS (http://creations-project.eu/), 16 partners from ten European countries develop creative approaches based on Art for an engaging science classroom. CREATIONS Program establishes a panEuropean network of scientists, teachers, artists, and students with the aim to improve the skills of young people in STEM (science, technology, engineering, mathematics) and to attract talent to scientific careers. As Li et al. (2020) mention, STEM education is not a well-defined field, while its combination to new pedagogical theories and Art (STEAM) is something really new in science education. According to Shernoff, Sinha, Bressler, and Ginsburg (2017), integrated approaches to STEM education can help the next generation of students to solve real-world problems by applying concepts that cut across disciplines as well as capacities of critical thinking, collaboration, and creativity. The CREATIONS Program aims to demonstrate innovative approaches and activities that involve teachers and students in scientific research through creative ways that are based on Art. The program focuses on the development of effective links and synergies between schools and research infrastructures in order to spark young people's interest in science. Teachers and students use and share in an innovative way the collective power of unique scientific resources (research facilities, scientific instruments, 
simulation and visualization applications, and scientific databases) in meaningful educational activities. The CREATIONS Program proposes the introduction of creative approaches in science education in order to generate alternative ideas and strategies within scientific inquiry as an individual or community. This is driven by a commitment to foster everyday creativity in students, such that they are engaged in purposive, imaginative activities that generate original and valuable outcomes. More specifically, the main objectives of this project are the following:

- Develop a pedagogical framework that builds on the essential features of creative learning including exploration, dynamics of discovery, student-led activity, engagement in scientifically oriented questions, formulations of evidence-based explanations, connection of explanations to scientific knowledge, and communication and justification of explanations. These elements support creativity as a generic element in the processual and communicative aspects of pedagogy by integrating culture and arts and proposing innovative teaching strategies. These strategies could increase student participation and enable them to generate highly imaginative products. The program promotes a series of educational activities that will utilize creativity and empowers students to actively engage in the learning process, improving their conceptual understanding in various scientific topics. It is therefore evident that the educational practices and strategies presented will allow science educators and specifically late primary and early secondary school teachers to identify creative activities in order to teach science. Furthermore, the proposed pedagogy aims to enable teachers to either create new creative activities or to properly assemble parts of different educational activities that are identified as creative (web-fests, virtual field trips based on game-based approaches, design of school-based exhibitions, junior science cafes, students artworks such as science theatre and operas) into interdisciplinary learning scenarios.

- Select a series of initiatives that successfully introduce the scientific methodology in school science education, by utilizing existing research infrastructures of research institutions and online tools. The CREATIONS initiative aims to create activities that provide access to CERN infrastructures (LHC, ATLAS, CMS) and with which the project partners are developing and testing for many years such innovative applications (supported by relevant materials and resources) that promote creative problem solving, discovery, learning by doing, experiential learning, critical thinking and creativity, and simulating the real scientific work. Based on the
CREATIONS pedagogical framework, these educational activities are enriched and expanded with creative approaches to develop artworks (exhibits, theatre, opera). The aim of this enrichment is to enhance student and teacher involvement in creative activities.

- Create virtual learning communities of teachers, students, artists, and researchers and involve them in extended episodes of playful learning.

- Implement the CREATIONS selected and proposed activities on a large scale in Europe and beyond.

- Systematically validate the proposed approaches and activities in order to identify their impact in terms of effectiveness and efficiency.

- Design and implement a systematic raising awareness strategy that will contribute to the effective communication of the project's results and outcomes.

The framework of The Stories of Tomorrow (STORIES) (http://www.storiesoftomorrow.eu/) is specifically designed for teaching professionals in STEM disciplines (Science, Technology, Engineering, and Mathematics). The STORIES is a research and development project funded by the European Commission, involving 15 project partners from 10 countries. The project uses the concept of storytelling as a catalyst for the effective interaction between Art and STEM disciplines which share similar values, similar themes, and similar characteristics. The STORIES project proposes the introduction of creative approaches in STEM education to generate alternative ideas and strategies within scientific inquiry as an individual or group, and it further encourages students to support them. The project designs and tests a new vision of teaching and helps to develop strategies for how teachers' roles and conditions can support and enable deeper learning for students. Therefore, the project includes and uses innovative and meaningful digital technologies, such as advanced interfaces, learning analytics, visualization dashboards, and augmented/virtual reality applications and builds a storytelling platform where students develop and publish stories about a Mars Mission. It will introduce teachers to the concept of digital storytelling as well as inquiry-based science teaching techniques in order to develop, improve, and enhance their teaching skills and practices. After more than 6 months of space exploration, including a travel to the Red Planet, colonizing Mars by designing and building Mars shelters, many hands-on experiments, and scheming rover missions on the Mars surface, crafting models of the solar system, and creating stories that showcase the full creativity and spirit of their age, the students presented their stories about their missions to the Mars. 
The program is creative itself, as students have to organize a hypothetical mission to Mars, having researched all the living circumstances on this planet, and they also have to write a digital story for their mission to Mars. Taking into consideration that Mars' exploration is not included in primary school curricula, the reasons why the program is creative and innovative become evident.

\section{Nature and context of scientific creativity}

There have been various studies on the nature of creativity over time, which spans many centuries and multiple disciplinary perspectives (Craft, 2005). Creativity is a complex and multifaceted phenomenon. Definitions of creativity include the pattern of creativity and its components. According to some researchers, scientific creativity constitutes the basis of knowledge production (Ghassib, 2010 quoted by Mumford et al., 2010). The creative cognition approach views creativity as the generation of authentic and original products through the application of basic cognitive processes to existing knowledge structures (Simonton, 2012; Ward, 2007). Assessing conceptual information and combining previously separate concepts means that students correlate connections with processes, structures, and creative outcomes. A dependent variable of central importance is the originality of the generated products. Aktamis and Ergin (2008) refer to scientific creativity as the ability to find new problems and formulate hypotheses. Torrance (1998) considers fluency, flexibility, and original thinking as central features of creativity. On the other hand, $\mathrm{Hu}$ and Adey (2002) approached scientific creativity in three dimensions consisting of (1) the production (technical production, scientific knowledge, scientific fact, and scientific problems), (2) the process (thinking and imagination), and (3) the feature (fluency, flexibility, and originality). Fluency means the number of original ideas produced that is how fast a person thinks to solve a problem and how fast and independently he/she can express his/her thoughts. Fluency can be measured in terms of the total number of responses related to the object (Sharma et al., 2017). Flexibility is the ability to "change tack," not to be bound by an established approach after that approach is found to no longer work efficiently. Students approach a situation differently and develop a number of different solutions regarding the problem. It allows children to experiment with their ideas, develop their creativity by allowing them to make mistakes so that their skills can be unleashed, developing a sense of wonder. Flexibility can be measured in terms of the total number of categories derived from the data (Sharma et al., 2017). Originality is interpreted statistically: an answer is considered original if it is rare, meaning that it occurs only occasionally in a given population. Innovation and uniqueness of answers are viewed as the basis of originality. Originality can be measured in terms of weights assigned in accordance with their degree of unusualness. The unusual responses can be defined as those responses which have a probability of occurrence to the extent of 5\% (Sharma et al., 2017). According to researchers, scientific creativity is different from other types of creativity, as there is a learning outcome related to scientific knowledge. Students deal with scientific problems, try to research, and collect data for their answers, and they act as researchers, combining their data, making scientific experiments, and giving scientifically correct answers. During this procedure, students change their cognitive frames by altering their scientific thinking. The procedure usually adds new elements to students' prior knowledge. Creative tasks are not defined as tasks in which students are entertained, but as tasks that students have to activate intellectual factors to give scientific solutions by getting emotionally involved and having fun. Students rely on prior scientific knowledge and try to expand it and apply it to their everyday lives. Aktamis and Ergin (2008) link scientific creativity to analytical intelligence as both of them originate from mental ability. In scientific creativity, students produce new ideas that are scientifically accepted by understanding scientific notions, solving scientific problems and designing experiments, or making artistic products using their imagination, fantasy, and originality. Creativity does not only involve the ability of representing a given problem, but it also involves identifying the real problem and representing it. It is in accordance with scientific skills, such as the identification of a problem, observation, collection of data, presentation of a scientific solution with different representative systems, and evaluation of the processes. Sharma (2017) defines creativity as the ability to correctly formulate research problems within a body of knowledge, an ability to create a comprehensive search space for the solution of a scientific problem, an ability to assemble (or induce) and implement heuristics to reduce the search space, patience, and stamina for the exhaustive attempt to solve the scientific problem within the constrained search space. Scientific creativity involves sensitivity to problems. Samsudin, Setyadin, Suhendi, Chandra, and Siahaan (2018) refer to scientific creativity as the procedure of studying scientific phenomena with different ways. At the same time, recent studies focus on the social dimension of creativity by bridging the gap between what already exists (i.e., "what is") and what constitutes the enactment of imagination (i.e., "what might be") that are considered both original and novel and also valuable (or useful) (Chappell et al., 2015; Chappell \& Craft, 2011; Mumford et al., 2010; Boden, 2009; Craft, 2005). Creativity is widely recognized as occurring along a 
continuum, at one end of which is what might be called every day, or "little c" creativity, which may be defined as inherently low in originality and low in wider impact. At the other end of the creativity continuum, reflecting high originality and high impact, one finds "big c" creativity. For Boden (2009), this is " $\mathrm{H}$ " creativity, in other words historical creativity, which actually generates such novel ideas that a paradigm shift occurs, or the world is changed.

In CREATIONS Project Art Education is positioned as a "holder" within which creative science education is being nurtured, grown, or "encultured" via arts practice. One of the main drivers for CREATIONS creativity is possibility thinking for all involved. This means being able to ask "what if" and "as if" questions (Chappell et al., 2015).

In STORIES project as students generate new ideas, they also trigger a change in them that transforms them to "makers"; they develop their identity, and they are embedded with the ethical awareness of their decisions.

The present study suggests a definition of creativity, taking into consideration some of its aspects that have not been described yet. Therefore, we have concluded that scientific creativity is a procedure in which all agencies and especially students use their scientific knowledge to produce original, authentic, creative, imaginary, and scientifically correct and acceptable products. But in this procedure, creative methods and processes are organized through basic principles according to subject domains. There is a balance between creative guidance and student imagination which has to be scientifically acceptable. Creativity requires a transformation of knowledge; therefore, creativity is a procedure which combines scientific principles of different subject domains and scientific fields, as it tries to represent this product using different semiotic systems. It refers to different representational systems which collaborate to produce a final learning product. The procedure of transformation is influenced by students' personal values, beliefs, and their social environment. Therefore, a creative procedure is influenced by social, cultural, ethnographical characteristics, and personal beliefs and ideas, which are socially constructed. Creative outcomes are original and valuable in relation to the learner. The student learns to generate ideas as an individual or as a member of a community, support his/ her products scientifically, and give scientific explanations. Student creativity means that students can combine aspects of different areas or subject domains (for example a scientific explanation of a phenomenon and its artistic representation) through an interdisciplinary approach in order to create new cognitive frames and meta-frames. While representing different notions through different semiotic systems, students enrich their creative product with their personal and social beliefs, adding new contexts to their initial intuitions.

\section{The significance of socio-emotional and socio-cultural factors in student creativity}

Apart from the process during which the student learns to represent scientific concepts, learning process needs to be accompanied by appropriate emotions. Students need to experience, to feel the represented concept. For this reason, emotion plays a significant role in stories. Perry and Medina (2011) suggest that students' recalling of past experiences and emotions is of great importance since it may affect the degree of embodiment of new scientific concepts. Students' past experiences are linked to their mental representations are embodied (Smyrnaiou et al., 2017) and expressed through cognitive actions, helping students to better understand the scientific concepts, their feelings, and the way the body can code and establish social norms as students find themselves in a verbal exchange. These pedagogical principles are affected by students' cultural beliefs and what we call socio-cultural context. Culturalism (Masemann, 2003) is one of the approaches of mind inspired by the fact that the mind could not exist separately from culture. The reality is represented by a symbolism shared by the members of a cultural community and refers to the habits of the past, the present, and the future. In this sense, culture is superorganic and shapes the minds of individuals as well. Although meanings are "in mind," they have their origins and their significance in the culture in which they are created. On this view, learning and thinking are always situated in a cultural setting and depend on the utilization of cultural resources. The students' cultural environment is built both based on their subjective perceptions and on the social and cultural environment in which they act as subjects. This study mostly focuses on the social and cultural environments. The notion of culture here illustrates the ideas and actions and constructs the students have nowadays. These beliefs affect their options and ideas about living in Mars, the future of humanity, the life in another planet, or even the way people act against the Earth itself, ecological issues, identity issues of humanity, etc. As a result, culturalism seeks to bring together insights from psychology, anthropology, linguistics, literature, and other human sciences in a scientific context. The cultural factor reflects the verbal, physical, and social presence of students, a fact which verifies its direct connection to multiple representational systems as the conceptual field is approached scientifically and is also connected to everyday life at the same time. The cultural factor contributes to the representation of scientific concepts since students depict altogether the historical, social, cultural, and scientific context while it is also linked to creativity, imagination, and Art. Semiotic analysis takes into account the factor of cultural identity. However, how the cultural context affects the formation of 
cognitive structures has not been studied yet (Smyrnaiou et al., 2018). According to Hewson (2000), the environment plays a key role in the recruitment of semiotics. The conceptual ecology (Toulmin, 1972) was introduced as a term to describe how the environment (cultural beliefs, considerations, events, etc.) affects the intake of knowledge. Mingers and Willcocks (2014) introduced the term socio-materiality to suggest that the material world interacts with cultural identity. Therefore, stories written by students are often inspired by cultural beliefs and ideas. Every time students say something in their stories, or make an utterance, they, at least, implicitly make claims that may be contentious. Mingers and Willcocks (2014) argued that these validity claims are of three types, and each one points to or refers to an aspect of the world, or rather analytically different worlds. These three types are (1) truth: concerning facts or possible states of affairs about the material world, (2) rightness: concerning valid norms of behavior in our social world, and (3) sincerity (truthfulness): concerning their personal world of feelings and intentions. Most students' stories are influenced by their everyday lives, the way they live in each country, or the way they have learnt to face the world. This truthfulness can actually be combined with the originality of ideas in their stories or even their creative attitudes.

\section{The context of digital storytelling}

Several research studies have shown that students learn when new cognitive concepts are established and when different semiotic systems are combined (Smyrnaiou et al., 2017). Digital storytelling is an interesting combination of how pedagogy and technology can be combined so as to increase student's ability to acquire scientific knowledge more sufficiently. Digital storytelling is a media artifact that combines a narrated audio text with still images to tell a story (Boase, 2008). This combination of language, visual, and digital representation is enriched with images, sound, and movie techniques and can create a powerful tool of cognitive development. According to Boase (2008), most effective digital stories are short: up to two and a half minutes long only, consisting of not more than 200-250 words. In effective stories of any media, there is usually a sense of causality and development or progression from one point to another and completion. The importance of having a story at the heart of a digital story-with a beginning, an end, and some development and interest between those points-is vital. The significance of digital storytelling in students' cognitive, emotional, and social development is crucial. By making a story, students have the opportunity to activate their internal cognitive mechanisms by external stimuli, related to their interests. The combination of different principles of subject domains is crucial. Stories are students' attempts to explain, understand, and account for experience. Experience does not automatically assume a narrative form; students construct stories reflecting on experience (Boase, 2008). In constructing a story, students firstly have to accept and integrate the scientific knowledge. This means that students should firstly observe and comprehend scientific knowledge. Then, they organize, classify, and analyze the main elements of scientific notions so as to be able to synthesize their cognitive frames. On the next phase, students represent scientific notions, and this representation is better when students combine different systems. Therefore, in digital storytelling students follow the principles of science, art, morphological, semantic, digital modelling, and narratives. Their texts are enriched with related pictures or sound that have to be in accordance with the scientific meaning. This procedure is improved when students are influenced by their emotional development and social interaction. As a result, their stories transfer their beliefs, their values, and their own perception of the world. They become the agent of their own knowledge, while they discover personal characteristics. Digital storytelling also implies a degree of critical awareness as students select information, gather evidence, describe scientific notions, present them in their own way, which has to be scientifically correct, and use the appropriate cognitive schemes to represent knowledge. Ultimately, critical thinking is the mental processes of discernment, analysis, and evaluation, which should combine scientific evidence with common sense. Narrative thinking also involves elements of uncertainty, inevitably since a story is a version of reality and truth and is open to interpretation. In the process of making digital stories, a student has to locate and put images and artifacts that meaningfully support the message of their text in order. This requires critical awareness of the meaning the story maker wishes to convey. This process incidentally increases students' media and technology literacy and helps them to develop a discerning eye to select resources. Digital storytelling is trumpeted as a useful tool in the promotion of deep learning (Boase, 2008). Deep learning, as opposed to surface learning, is a term used to describe the kind of learning process that involves the critical analysis of new ideas; deep learning also links them to already known concepts and principles, which leads to understanding and longterm retention of concepts so that they can be used for problem solving in unfamiliar contexts.

\section{Three scientific creativity tests The research tools}

In the present study, three scientific, research tools of scientific creativity through digital storytelling have been developed, and they create a new qualitative model of 
creativity (Smyrnaiou Z and Georgakopoulou E, The methodology of designing tools for qualitative analysis in educational studies (unpublished observations)), the Creative, Cognitive, Qualitative Model for Creativity (CCQ tool). This model of three practice tools was constructed in order to combine the basic principles of scientific creativity as they are presented and examined through CREATIONS and STORIES European Research Programs. Our aim is to evaluate the development of student creativity while students engage in scientific digital storytelling.

The first research tool has been designed based on two already validated creativity tests: the Scientific Structure Creativity Model (SSCM $(\mathrm{Hu}, 2002)$ and the Torrance Tests of Creative Thinking (TTCT) instruments (Kim, 2017). However, we have expanded these tools by combining each of their elements and categories to the main features of creativity as they have developed in the CREATIONS Program. The need to create a new tool arose from the fact that there is no evaluation tool that specifically qualitatively measures scientific creativity in primary school graders.

\section{First theoretical tool of creativity \\ The Torrance Tests of Creative Thinking (TTCT)}

The TTCT (Kim, 2017) is composed of creative thinking skills and creative attitudes (Table 1). The Creative Thinking skills are classified in three categories, namely, ION which are required for innovation (Kim, 2017): (1) inbox, which helps develop expertise; (2) outbox, which helps imagine numerous and diverse possibilities to develop unique ideas; and (3) Newbox, which combines elements of inbox and outbox thinking to create new output.

In Inbox thinking, expertise is the complete and indepth understanding of a topic or subject. Inbox thinking means that students have to use their prior knowledge to comprehend something new and try to solve real-world problems. This procedure also requires critical thinking, as students have to combine prior knowledge with situations that are new to them.

The Outbox imagination means that students start thinking outside of the box. Students research what activities have to do in order to produce creative output by using inquiry, making assumptions, and testing their ideas. Fluent, flexible, and original imagination are significant parts of outbox imagination, as students have to produce many ideas (the amount of ideas), combine

Table 1 TTCT model (Kim, 2017)

\begin{tabular}{|c|c|}
\hline \multicolumn{2}{|c|}{ Creative thinking skills and attitudes (TTCT model) } \\
\hline Inbox & Expertise development and critical thinking \\
\hline Outbox & Fluent imagination, flexible imagination, original imagination \\
\hline Newbox & Synthesis, transformation, promotion \\
\hline
\end{tabular}

Open-minded, playful, emotional, daydreaming different tasks, consider many options of a situation (their ability to be flexible by finding different internal mechanisms of different solutions), and generate new, original, and unusual ideas (innovative ideas).

The Newbox connection is the last step of creative procedures. Students have to link prior knowledge to new conclusions. This means that they try to establish new cognitive frames. Students transform what they have learned into creative products. According to Kim (2017), the final level of creativity consists of (a) synthesis of old and new elements using different semiotic systems (verbal, non-verbal, embodied learning, visualization), (b) transformation into a final product that is different than students' initial assumptions and beliefs, and (c) promotion, which means that a creation must be promoted in the right place and time in order to be considered unique and useful.

The second part of Torrance's tool (Kim, 2017) describes creative attitudes, for example, open-minded, emotional, playful, daydreaming, and nonconforming attitude. This categorization differs from traditional ways of thinking; it examines whether students dare to broaden their experiences, express their feelings and emotions when they investigate a situation, explore all the facts and parameters to reach safe conclusions, and make unrealistic but goal-oriented decisions.

\section{The Scientific Structure Creativity Model (SSCM) instrument}

$\mathrm{Hu}$ and Adey (2002) suggest the Scientific Creativity Structure Model (SSCM) in an attempt to measure creativity (Fig. 1). Their opinion that creativity is defined as the sense of going beyond existing knowledge and techniques and creates new understandings means that it is combined with problem- solving theories, cognitive theories regarding student development, student motivation, imagination, and the role of Art in STEAM

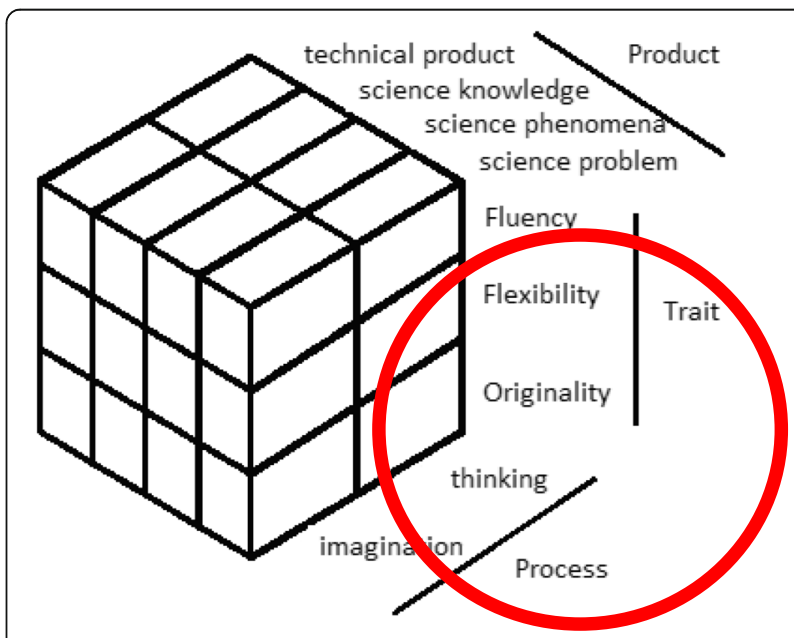

Fig. 1 The Scientific Structure Creativity Model (Hu and Adey, 2002) 
education. This model is a three-dimensional model with 24 cells that represent scientific creativity. Each cell is a combination of a process, a trait, and a product. The collateral features identified between the Scientific Structure Creativity Model (SSCM) and the TTCT are the trait and process features that are closely linked to the outbox and inbox categories according to the TTCT.

In our research design of creating theoretical, qualitative research tools, we initially compared these two tools, trying to find common codes. Following a thematic analysis, we detected common areas. By comparing the two tools, we easily identify common areas of reference. The last area of the SSCM, the product area, addresses the elements of transformation and synthesis found in the TTCT. It is a domain area which is restricted to encompass scientifically oriented technical products. In the present study, we proceed with a content analysis of students' digital storytelling in order to trace and monitor the degree of their creativity. However, the overlapping of categories between the tools strengthens the validity of our newly developed creativity assessment tool regarding its measuring objective: creativity in the scientific context.

In the trait dimension in SSCM, fluency is defined as the number of ideas produced. In the present research context, the more scientific ideas a student produces, the greater his/ her fluency becomes. Flexibility is defined as the ability to not be tied to orthodox approaches if they are no longer efficient. This means a student with greater flexibility traits tends to search for ideas through different categories or approaches. Lastly, originality is defined as an answer that is statistically rare, occurring only occasionally in a given population sample. Therefore, a student that gives rare but appropriate answers to a question is considered to have higher originality traits than other students.

The process dimension of SSCM reflects a series of intellectual mental operations by an individual to produce creative product(s) with their trait dimension. Its two central features are called creative imagination and creative thinking. Creative imagination is associated with using explorative mental operations that lead to new and related ideas (Craft, 2005; Sefertzi, 2000). A strong difference between the two instruments is the absence of creative attitude measured in the SSCM. However, the interactive and reciprocal relation among the Inbox-Outbox-Newbox categories of TTCT and the process dimension regarding SSCM is a strong similarity that the two instruments share.

\section{CREATIONS key features}

According to the CREATIONS definition of creativity in science education, creativity is a "Purposive and imaginative activity generating outcomes that are original and valuable in relation to the learner. This occurs through critical reasoning using the available evidence to generate ideas, explanations and strategies as an individual or community, whilst acknowledging the role of risk and emotions in interdisciplinary contexts" (Chappell et al., 2015). Based on this notion, 8 CREATIONS features have been formed, which act as generic categories in our evaluation tool strengthening the notion of creativity as follows:

1. Dialogue: Dialogue refers to appropriate questions which lead to new ideas. By engaging in a dialogue, students are encouraged to act and try to combine prior ideas to new contexts.

2. Interdisciplinarity: This is grounded in the interrelationship between different ways of thinking and knowing which means allowing space for different ways of thinking (e.g., problem-finding, exploring, reasoning, reflecting, questioning, experimenting) around shared arts/science threads or through lines. Interdisciplinarity means that students are encouraged to find solutions to problems, following the principles of inquiry and try to answer real problems from every-day life.

3. Individual, collaborative, and communal activities for change: It means addressing communal engagement with a shared creative process and purpose. Therefore, student collaboration is needed to produce creative products.

4. Balance and navigation: balancing control and freedom, structure, and openness means that students are constantly in a process of creating their conceptions both individually and by interacting with other students. Students have to balance prior knowledge to the new one, ask their own questions but also generate scientifically correct ideas. Balance can also be about integrating existing scientific knowledge with engaging or enlightening arts processes so that children and young people's own everyday questions about the world are brought to life.

5. Empowerment and agency: these enable student agency and encourage children to try out (and critique) their own ideas and questions in investigations,

6. Risk, immersion, and play: creating a trusting space in which mistakes are possible with no fear of failure.

7. Possibilities: Practice can allow for multiple possibilities both in terms of thinking and spaces and broaden student minds in the context of asking "what if" questions.

8. Ethics and trusteeship: Learners consider the ethics of their creative science processes and products and are guided in their decision-making by what matters to them as a community, acting as "trustees" of that decision-making and its outcomes.

As in the TTCT and SSCM tools, the CREATIONS features are not presented in any intentional hierarchy; 
they rather involve a highly organic process, in which all of the features are connected via professional wisdom.

\section{Effective learning environments}

In order to measure creativity, we have to examine both the creative procedures and the creative products. Therefore, we have created a series of effective learning environments (Smyrnaiou \& Sotiriou, 2016) in CREATIONS Program. They are creative contexts that can support teaching science by creativity-enriched inquiry. As far the design and structuring of CREATIONS Learning Environments are concerned, they act as a hub to enable the development of educational and outreach activities in the form of CREATIONS demonstrators. Their characteristics are the following:

- identification of the ability of leaning environments to support the requirements established by the CREATIONS pedagogical framework and principles

- presentation of the learning environments creative and innovative affordances

- setting the context of their implementation and usage, considering their contribution to the learning process and their exploitation by students, teachers (both university and school teachers), policy makers, and stakeholders that have adopted a creative and inquirybased approach.

In addition to the above key elements, the structure and underlying characteristics of the CREATIONS learning environments have been identified by also considering: (1) partners' inputs regarding the specific focus area of the learning environments and their characteristics and inputs regarding the context of the CREATIONS initiatives, (2) relative EU projects, and (3) literature review of key elements and characteristics of the design of effective learning environments that enhance creativity and inquiry-based approaches.

As a result, the following 7 types of learning environments have been created (Table 2):

1. Communities of practice (web-based/physical) aiming to develop a network of online communities and channels sharing multicast activities inspired by science on national or international level.

2. Simulations aiming to enable the visualization of theoretical models and facilitate inquiry-based experimentation.

3. Arts-based activities which address and enhance a scientific interconnection between science and aspects of art.

4. Dialogic space/argumentation aiming to engage students in argumentation and dialogic processes for a
Table 2 CREATIONS features of creativity and effective learning environments

\begin{tabular}{ll}
\hline \multicolumn{2}{l}{ CREATIONS pedagogical framework } \\
\hline CREATIONS features & Effective learning environments \\
- Dialogue & - Communities of practice \\
- Interdisciplinarity & - Simulations \\
- Individual, collaborative, and & - Arts-based \\
communal activities for change & - Dialogic Space/argumentation \\
- Balance and navigation & - Experimentation (science \\
- Empowerment and agency & laboratories and eScience \\
- Risk, immersion, and play & applications) \\
- Possibilities & - Visits to research centers (virtual/ \\
- Ethics and trusteeship & physical) \\
& - Communication of scientific ideas \\
& to audience \\
\hline
\end{tabular}

better insight into the nature of scientific enquiry and how scientists work.

5. Experimentation (science laboratories and eScience applications) aiming to enhance student physical and intellectual interaction with instructional materials through "hands on" experimentation and "minds on" reflection.

6. Visits to research centers (virtual/physical) aiming to connect the science classroom with research infrastructures, addressing the enhancement of informal learning settings.

7. Communication of scientific ideas to audience addressing the need to establish settings in which learners will be encouraged to externalize and elaborate on scientific concepts they have acquired while interacting with an audience (learners, teachers, scientists, parents, etc.), thus, promoting a dual channel of communication: (a) reflective processes (self-engagement for scientific consistency and verification) and (b) explicit elaboration of scientific ideas through interaction and "extroversion."

Although these types of learning environments formulate concrete ways of approaching creativity-enriched inquiry, they are structured in a flexible and overlapping way which allows for multiple entries and exploitations.

In an attempt to conclude to a common way to measure creativity, we used a thematic analysis in order to detect common codes between the existing tools and the features of creativity that we have examined in CREATIONS Program. Therefore, based on the TTCT model, the SSCM model and the CREATIONS model of creativity, we have created the following theoretical tool (Table 3). CREATIONS features are combined with the TTCT and SSCM models; we notice that despite their similarities, the three models have some strong differences. First of all, creative attitudes is a unique area that we can take into consideration, in order to understand students' preferences when they create a product. Secondly, in CREATIONS features collaboration between students plays a catalytic role in the production of 
Table 3 Analytical categories for CCQ tool

\begin{tabular}{|c|c|c|c|c|}
\hline \multirow{2}{*}{$\begin{array}{l}\text { CREATIONS features } \\
\text { Balance and navigation }\end{array}$} & \multicolumn{2}{|c|}{ SSCM Model } & \multicolumn{2}{|c|}{$\begin{array}{l}\text { Creative thinking skills and attitudes } \\
\text { (TCTT Model) }\end{array}$} \\
\hline & Process & Imagination, thinking & Inbox & $\begin{array}{l}\text { Expertise development, critical } \\
\text { thinking }\end{array}$ \\
\hline Possibilities & Trait & Fluency, flexibility, originality & Outbox & $\begin{array}{l}\text { Fluent imagination, flexible } \\
\text { imagination, original imagination }\end{array}$ \\
\hline \multirow{2}{*}{$\begin{array}{l}\text { Dialogue } \\
\text { Interdisciplinarity } \\
\text { Individual, collaborative, and } \\
\text { communal activities for change } \\
\text { Empowerment and agency }\end{array}$} & Process & Imagination, thinking & \multirow[t]{2}{*}{ Newbox } & Synthesis, transformation, promotion \\
\hline & Product & $\begin{array}{l}\text { Science, knowledge, science, phenomena, } \\
\text { science problem, technical product }\end{array}$ & & \\
\hline New categories for creativity & \multicolumn{2}{|c|}{$\begin{array}{l}\text { New categories of creativity- effective learning } \\
\text { environments }\end{array}$} & \multicolumn{2}{|c|}{ Creative attitudes } \\
\hline $\begin{array}{l}\text { Risk, immersion, and play } \\
\text { Ethics and trusteeship }\end{array}$ & \multicolumn{2}{|c|}{$\begin{array}{l}\text { 1. Communities of practice (web-based/physical) } \\
\text { 2. Simulations } \\
\text { 3. Arts-based } \\
\text { 4. Dialogic space/argumentation } \\
\text { 5. Experimentation (science laboratories and eScience } \\
\text { applications) } \\
\text { 6. Visits to research centers (virtual/physical) } \\
\text { 7. Communication of scientific ideas to an audience }\end{array}$} & \multicolumn{2}{|c|}{ Open-minded, playful, emotional, daydreaming } \\
\hline
\end{tabular}

creative outcome. Creativity is an individual procedure, in which each student acts according to his/her internal cognitive mechanisms of thinking, but at the same time students have to collaborate with each other, to discuss their beliefs and exchange ideas, in order to produce creative and innovative stories. The third difference, which constitutes our contribution to the research tool, is the effective learning environments, the contexts in which students have to act in order to produce creative output. They are linked to modern pedagogical principles and propose different ways of acquiring and representing scientific knowledge. Effective environments confirm that the collaboration of simulations, artbased activities, argumentation, experimentation, and the visits to research centers or even holding communities of practice give birth to creativity. In the communities of practice learning environment, students can present their projects or group discussions to teachers, students, and mentors. Students cooperate with each other and communicate through digital platforms with other scientists, artists, teachers, and students. This way, they develop a network of online communities and channels sharing multicast-activities inspired by science on a national or international level. Simulations refer to the visualization of learning outcomes. Visual semiotic systems refer to systems that are not verbal, but they actually have an aesthetic similarity to what they represent. The term image/visualization can be used both for internal images (which is crucial, as students represent or make an image of a scientific notion according to their internal thinking mechanisms) and for schematic representations/external images/pictures (this refers to imaging, kinesthetic, schematic representations). Visual representations also include every type of picture, diagrams, maps, and computational images and are linked to analogies and models, diagrams and graphs, three-dimensional models, computational modeling, and simulative activities, which compare structures between different domains. Comparisons are part of our cognitive system; thus, they are a central tool for human language, logic, and knowledge and play an active role in acquiring knowledge. Interactions with external, imaging representations are important as they facilitate the construction of powerful internal imaging systems for students; hence, they assemble three key features: (a) facilitating the students' cognitive commitment to what is being taught, (b) allowing the students' cognitive development according to the learning procedure, and (c) allowing the assimilation of different forms of information. Semiotic system of visualization and simulation plays an important role in the last function of assimilation of information. In dialogic space and argumentation learning environments, students discuss and provide evidence of different sides of an issue; they try to give answers to ethical issues or link the scientific data and provide arguments about possible uses of science in everyday life. Argumentation competences are really important to student cognitive development. Dialogical procedure is linked to verbal representations of all related information to learning. This semiotic system is based on students' skills like labelling, explaining, analyzing, organizing their thoughts, and expressing their opinions according to scientific arguments. Making arguments depends not only on pre-existing and-in some cases, culturally influenced data and perceptions-but also on a language of augmented cognition. The mental frames that are denominated are different than the same uninformed mental frames. The question is whether language enhances these mental frames. Our cognitive representations are under the continuous influence of language and non-verbal elements (such as visual memory, object recognition, and tangible learning). Since verbal 
representation influences our cognitive framework, by changing verbal variables, some areas of representation will be affected. Our experiences match the words. Therefore, students learn to act between real thinking, mental thinking, and symbolic world. Verbal representation is a prerequisite for linking all other systems. In fact, the existence of verbal support leads to successful connections of the scientific theories to students' aspirations (Smyrnaiou, Sotiriou, Sotiriou, Georgakopoulou, 2017, 2016). If this is lacking, then students cannot represent the concepts (Smyrnaiou, Sotiriou, Sotiriou, Georgakopoulou, 2017, 2016). In experimentation setting (science laboratories, eScience applications), the hand-on activities were divided into pre-lab and lab phases and helped students to rely on true and real data in order to find answers to scientific questions. They can give crisis-related solutions and understand the meaning of learning science. Visit to research centers (virtual/physical) is an effective learning environment which is strongly related to the collaboration between schools and research centers. Communication of scientific ideas to audience is also a learning environment which is common in the majority of the demonstrators, as in phase 6 of inquiry-based approach students deal with different ways of thinking and possibilities and prove their ideas by providing justifications through dialogues with other students, educators, and professional scientists. Such communication is crucial to an ethical approach to working scientifically. Art-based activities are the central part of effective learning environments, as students link scientific activities to artistic representations.

\section{Second tool: students' creativity evaluation model research tool}

The second tool "Students' Creativity Evaluation Model" tries to combine different cognitive domains through an interdisciplinary approach to the representation of scientific notions through Information-Communication-Technology Tools and different semiotic systems, such as visualization and models, researching expected, and original and innovative ways of students' thinking. According to Foster, Wigner, Lande, and Jordan (2018), interdisciplinary projects framed by personal interest can lead to new ways of learning practical ingenuity, creativity, and some analytic skills.

The students' research tool consists of three main categories: (1) cognitive subjects (content/interdisciplinarity), (2) Information-Communication-Technology Tools, and (3) different visualizations of scientific ideas such as videos, pictures, and drawings regarding their content and manipulation. These three main categories (see Appendix, Table 5) are divided into expected, original, and innovate parameters, because every new perspective of each story has its origins in students' prior knowledge and beliefs (expected factor), and it is enriched with authentic and original ideas that students deal with so as to be able to reach innovate and creative ideas at the end. Innovative characteristics are linked to creative thinking skills and creative attitudes. During the analysis procedure, three new categories derived from the data, the socio-cultural factor, the socio-emotional factor, and the role of extracurricular activities.

\section{Third tool: experts' creativity evaluation model research tool}

The third tool "Experts' Creativity Evaluation Model" examines the role of experts' thinking on writing a story, and it aims to track experts' model of thinking, comparing it to the students' creative model of thinking. In the present study, one professor/researcher from the university and one independent researcher evaluated the stories. In school communities, the experts could be the teachers of each class.

Experts' research tool is inspired by studies that compare students' initial thinking and experts'/teachers' thinking. In this study, we try to find what characteristics "ideal stories" written from experts have and how these stories could be combined and compared with students' stories. This approach could help us to identify possible models of thinking and improve student creativity. The initial point of holding a story is the subject/cognitive domain. Scientific notions are the first category and are described along these stories. Habitability factors are combined with scientific content. These factors are expanded with professional content, referring to previous or future missions on Mars and anthropological content, which refers to socio-cultural factors and social beliefs. Artistic content is also crucial because it refers to another representative system, and because it can be combined with creativity features. Scientific content is enriched with Information-Communication-Technology Tools/Multimedia/Technologies (second category), which helps students to express their ideas, and socio-emotional aspects (third category). The last one refers to societal, emotional, and psychological aspects.

\section{Participants}

The Stories of Tomorrow is specifically designed to teach STEM disciplines (Science, Technology, Engineering, and Mathematics) professionals. It introduces teachers to the concept of digital storytelling as well as inquiry-based science teaching techniques in order to develop, improve, and enhance their teaching skills and practices. The project uses the concept of storytelling as a catalyst for the effective interaction between Art and STEM disciplines which share similar values, similar themes, and similar characteristics. The project designs and tests a new vision of teaching and helps to develop strategies for how teachers' roles and conditions can support and enable student deeper learning. Consequently, the project includes and uses innovative and meaningful digital technologies and builds a storytelling platform where students develop and publish stories about a Mars Mission. For instance, students stated which professionals they would like to follow them on Mars, what things from their life on Earth they would take with them, which relatives 
or friends they would take with them on Mars, and what actions they would organize there. As the project is still in progress, we will only present the first pilot research. In this research, we analyzed stories from the six different countries that participated in the program. We selected two classrooms from each country, while each classroom had 25 students. Thus, 12 stories written by primary school students (age 812 years old) are analyzed indicatively. Stories from different countries were chosen in order for the cultural factor to be examined as well. The sample is much bigger, but the main aim of this research is to provide a holistic research tool to measure student creativity qualitatively (Gobo, 2005). This sample allows us to examine the internal mechanisms of creativity, as we follow the principle of qualitative research (Smyrnaiou Z and Georgakopoulou E, The methodology of designing tools for qualitative analysis in educational studies (unpublished observations)). Three different research tools are examined by two independent researchers in order to examine all the factors derived from our definition of creativity as a complicated and cognitive procedure. These research tools represent conceptual and perceptual categorizations, but at the same time they can be used as a useful tool for the educational community and researchers in order to systemize creative scientific thinking.

\section{Research Design}

These three models are applied to examine qualitatively the scientific creativity developed by experts, teachers, and primary school students when they produce digital stories about their missions on Mars.

As described above, the three-dimensional research tool used in the present study involves a combination of collateral features that exist in two already validated creativity tests: the Torrance Tests of Creative Thinking (TTCT) and the Scientific Structure Creativity Model (SSCM) instruments, presented by us in a different way. We have compared the two models, and we have enriched them with our definition of creativity, its features, and the effective learning environments. We firstly used the thematic analysis in order to identify, analyze, and report patterns (themes) within the data, which were the creativity categories. We used this methodology, as we tried to identify the underlying ideas and conceptualizations of creativity categories and highlight if there were deeper connections between the existing categories of creativity of SSCM tool and TTCT tool to our categories of creativity as they have researched in CREATIONS Program. Searching, reviewing, and defining the themes was made with analytical way. As far as the second and third tools (students' and experts' model) are concerned, we followed a different procedure, coding their categories from the empirical data according to the Grounded Theory. In the applied tool for this research study, we use (1) the categories of monitoring creativity from the TTCT and SSCM models, (2) we focus on the overlapping elements between TTCT and SSCM model in order to strengthen the notion of scientific creativity, and (3) we extend the meaning of the involved categories by inserting the CREATIONS key principles as a state-ofthe-art update to strengthen the notion of creativity. Finally, we introduce effective learning environments as the creative context in which students have to act and react to each other in order to represent scientific notions creatively, using different semiotic systems. Following the phases of thematic analysis (Braun et al., 2019), in the first phase (familiarizing ourselves with the data), we read the data multiple times, noting our initial ideas. During the analysis, we tried to find common notions between the stories, common patterns that are repeated. In the second phase, the generating of initial codes, we coded interesting features of the data in a systematic fashion across the entire data set, collating data relevant to each code. The production of codes helped us to understand some common elements of creativity which appeared in all stories. Searching for themes and reviewing these themes led us to collate codes into potential themes, gathering all data relevant to each potential theme and to check if these themes worked in relation to the coded extracts and the entire data set. As a result, we managed to create a thematic map with some basic creativity features, and then we defined and named these themes according to the categories of our research tools. As a result, we had clear definitions and names of each theme, closely related to the categories of creativity that had to be researched according to our theoretical framework. During the last phase, we tried to extract examples related to the analysis of our research question.

As the written stories are categorized in verbal data, content analysis (Krippendorf, 2018) helped us to examine if the way students used the language and wrote their stories could reveal their mental representations and some types of creative attitudes. Moreover, students' linguistic choices and their opinions reveal their cultural beliefs and allow us to examine the socio-cultural factor in the stories. Coding some phrases or words from students' stories helped us to examine how students express their creative thinking verbally and then to combine this verbal representation with other representational systems, such as digital storytelling and the use of ICT tools.

During this procedure, new categories were revealed and added to the theoretical framework; therefore, the Grounded Theory approach enriched the categories of creativity skills. This "mix-method design" leads us to more specific results and enables a mutual validation of qualitative results by providing a clear rationale of choosing each method. It is worth mentioning that these different methodological approaches have to be used at the same time, especially as we examined the cognitive procedures which students follow in order to represent scientific notions in a creative way. This middlerange theory helped us to understand and explain student behavior and processes and make comparisons of (1) data, (2) data and codes, and (3) concepts. The first research tool 
is theoretical and tries to standardize creativity; the second tool refers to students and derives from empirical data, and the third research tool refers to 3 experts who have decided to write stories about missions on Mars and have followed inquiry-based processes. This process was followed by two independent researchers, who later compared their findings and completed the categories of creativity.

\section{Results}

Twelve (12) student stories from classrooms of different countries which participated to the STORIES Program are analyzed indicatively by two independent researchers. The results seem to indicate that digital storytelling increases scientific creativity among students. Students' creative thinking can be qualitatively evaluated, as students have written innovative and authentic stories. Their stories are enriched with multimodal texts, such as pictures, videos, and graphics. Most of the stories are scientifically acceptable. Students generate new and original ideas, and they use verbal, non-verbal, digital, and aesthetic representational, cognitive systems to express their ideas. The proposed tools analyze student creativity, as they focus on the students' cognitive representations; the prior knowledge students are based on in order to comprehend new conditions and student ability to think out of the box. Digital storytelling is a demanding procedure, especially in really new contexts, such as the life on Mars. It was observed that students combined a variety of skills to produce innovative and scientifically correct stories. The final stories confirm student cognitive development.

Inbox Category seems to appear in all stories $(100 \%)$ (see Appendix, Table 4). This percentage indicates the highly motivating challenge the students are engaged in. The main theme of the stories, a mission to Mars, is not usually a part of formal curricula, especially in primary schools; thus, including it is also innovative itself. Students show a tendency to use prior knowledge and beliefs as they engage in creative writing and elaborate their ideas using scientific concepts. This way, they shape a safe zone as they proceed to unknown territories. As a result, students scientifically support their ideas and options. Story content was scientifically acceptable. Scientific details about Mars are mentioned, such as the size, the light atmosphere, the low levels of gravity, the craters and satellites, and even the volcano Olympus Mons. Students mentioned that suitable suits for their mission to Mars had to be perfectly designed, so as to reflect heat, and make it possible for the astronaut to carry the necessary equipment. As far as the spacecrafts are concerned, they must have enough space for all the appropriate tools and the crew. The main training of the astronaut was another common theme in stories. Almost all students provided explanations about this exhausting but necessary stage in order for the astronauts to be ready and prepared for different situations. In some cases, students expanded their knowledge by providing a number of examples of special conditions such as the lack of gravity. The course of crew's education included training in special space conditions. This point was very crucial to students as they have to represent real training conditions. Therefore, it seems that they have studied details about astronauts' training (Figs. 1, 2, 3, and 4), and the majority of students managed to find ways to represent it, proving that they were able to apply what they had learned. After the main training, students organized the first phase of preparation of a journey. Results have shown that predicting the whole phases of an unknown experience and organizing each possible detail demand high levels of knowledge. The preparation phase included making predictions and measures about safety rules, calculating fuel supplies, predicting possible dangers, sharing possible responsibilities to the crew according to each profession, and organizing the first steps on Mars such as taking photographs, gathering possible data, (temperature levels), and finding a suitable location for greenhouses to be built. It seems that the main rules of surviving and living were taken into account by all students. Students studied the conditions on Mars, acting as scientists, stating that they may send robots to study the sand storms, the solar storms, the ground, etc. During the mission on Mars, students had predicted the responsibilities inside the spacecraft, such as communication to Earth, the crew's physical state, and had studied and measured the distances in space. In some cases, they had thought about possible solutions to damages in spacecrafts such as thermal insulation. Students also include scientific data, applying their knowledge, even when they are on Mars. The heroes of the stories collect data from the surface of Mars, build energy and water systems, or even find ways to create an artificial atmosphere on Mars with magnetic fields. Some stories also mentioned the option of building greenhouses for plants to grow using fertilizers and the need for food supplies.

As far as the Outbox Category is concerned, fluent imagination appeared in all stories (100\%). This percentage indicates that students were motivated by this theme which stimulated them to think "out of the box" (see Appendix, Table 4). Students have managed to generate many ideas in order to solve the problem of realizing a mission to Mars. Approximately, 71.4\% of the stories are characterized by flexible imagination. This shows that students do not only use the existed knowledge, but they started to consider multiple options regarding the complexity of the theme. The students created problems in their stories that need to be solved (e.g., find alternative sources of energy in case they run out of fuel, create favorable 


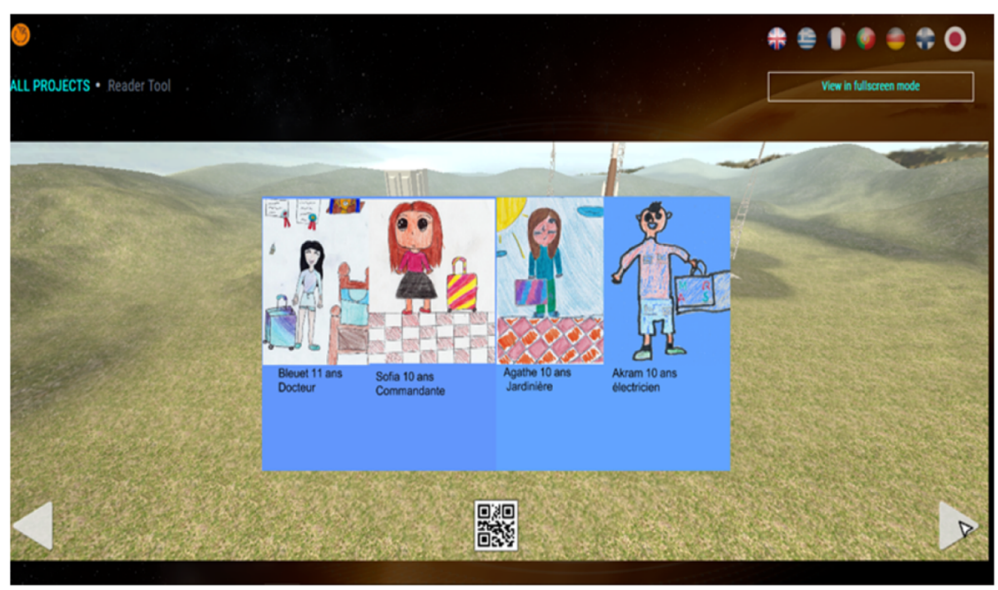

Fig. 2 An example of a student's story referring to astronaut's preparation

conditions for human colonization of Mars, etc.). Original imagination that addresses the application of unusual ideas appeared in a small number of stories (16\%). This means that students, at least in their first attempts of writing a story, do not feel comfortable enough to express themselves in an unusual way. This could be due to the fact that they are afraid that their stories will not make sense to the readers or that their stories will not be scientifically correct. Therefore, it could be suggested that students are urged by their educators to feel free to improvise by creating problems and solutions beyond an expected content. However, it has to be mentioned that wherever unusual ideas are included, like the help of robots or people's collaboration with robots, these ideas are totally in accordance with the framework of the story. Fluent imagination is confirmed in almost all stories as they refer to the following:

a) The preparation before the mission: For example, some heroes mentioned that they would take photos of their families and gifts from their friends with them. b) The training phase: This phase on Earth consists of calculations about the distance between the Earth and Mars with the help of the Sun's orbit, model representation of greenhouses, or even the simulation of psychometric tests and logical tests for astronaut preparation and training. Students mentioned that the astronauts must be calm, sociable and clever, and able to survive in extreme conditions. They should have scientific skills, while training should last more than 7 years.

c) The mission phase: In some stories, the crew members had to deal with unexpected parameters, like running out of fuels while returning back to Earth, and in other stories the crew members discussed with "Martian people" and learned their beliefs about humanity.

d) The future phase: In some stories, students expanded their thinking and referred to future colonies on Mars, or even the destruction of the Earth.

At the same time, flexible imagination is confirmed by the existence of multiple professions as students seem to find different options of facing possible problems. Another crucial factor is their mixed feelings (happiness for

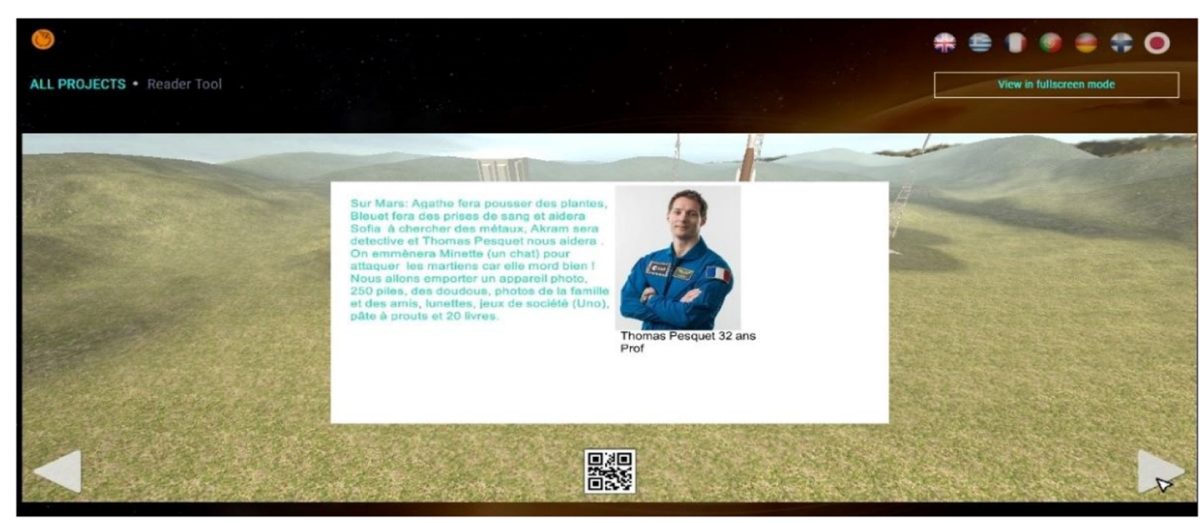

Fig. 3 An example of a student's story referring to astronaut's preparation 


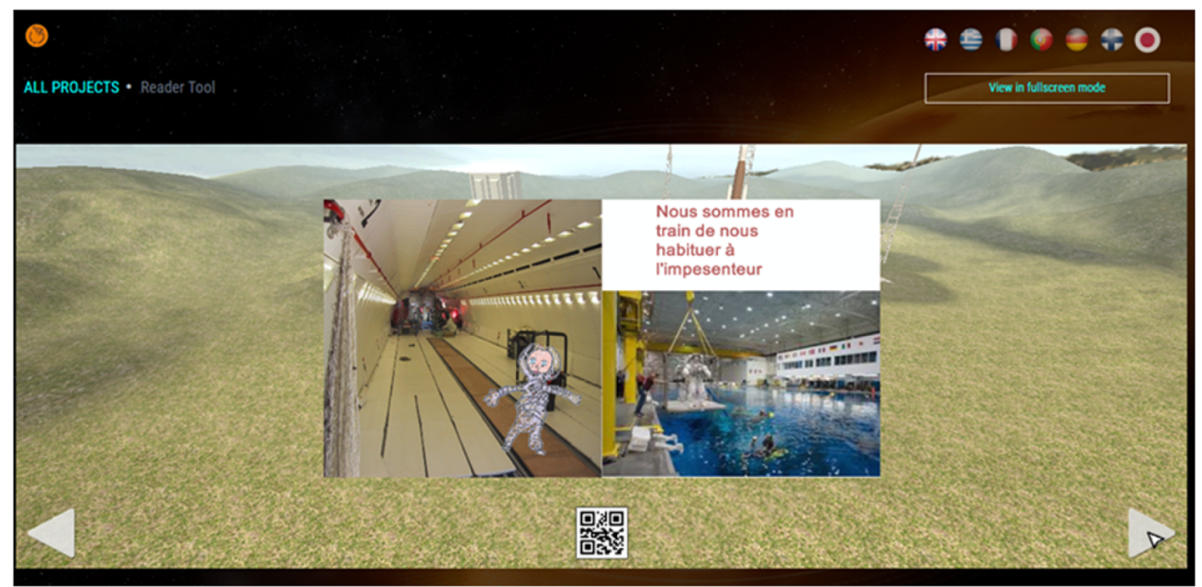

Fig. 4 An example of a student's story referring to astronaut's preparation

the next step-sadness for their families-anxiety about the future) about the mission to Mars. Multiple solutions to possible problems also confirm high levels of student flexibility. Students suggested that crew members should build nuclear reactors on Mars so that nuclear power could be generated. They also highlight the need for special equipment for water supplies, the need to repair rovers, have batteries for wind turbines and construct a new type of vehicle to protect astronauts from dust storms. In some other stories, students used stones from Mars as natural fuel, and they treated an infection in the colony by taking samples and sending data to Earth. Some students took into consideration the principles of storytelling, so flexible imagination exists also in the beginning of the stories (e.g., a father announced to his family that he had to go to Mars, and the children decided to follow him without saying anything).

Original imagination is the heart of creative processes as students generate new or unusual ideas. In some stories crew members discussed with aliens; some of these aliens were presented as bad creatures while others as being friendlier. In other stories, crew members had to deal with new everyday life on Mars; therefore, they were challenged to learn how to walk or eat. People's cooperation with robots is another innovative idea that is presented in stories, along with the construction of special vehicles to protect the members of the mission.

Newbox thinking (see Appendix, Table 4) is the last category measuring students' creative thinking. The Newbox category has been analyzed regarding its subcategories: (1) In the synthesis subcategory: Students tried to go beyond a subject, combining knowledge from different professionals; (ii) Metaphorical thinking (57.1\%): Half of the stories analyzed elaborate on ideas viewed from new perspectives (e.g. colonization on Mars seen over time, imaginative cycle of water, etc.); (iii) Nonverbal thinking $(100 \%)$ is highly used by students, probably because pictures and drawings are artistic activities and belong to their common interests (out of school activities); and (iv) five sense-thinking (35.7\%) which addresses that videos were not commonly used by students, probably due to the priorities given by the students, the amount of time required for the students to visualize their ideas, the available tools, students' familiarity with the tools, and last but not least the difficulty to visualize concepts that they had neither seen, nor experienced before in a way that is scientifically grounded. For this reason, we suggest that further samples of students' digital stories should be analyzed after students spend a significant amount of time in the use of the specific platform in writing more than one stories, and (v) Body thinking (7.1\%): Representing ideas with innovative videos, or motion pictures might be difficult for primary school students (see also five sense-thinking above). (2) In the transformation subcategory: (i) Students try to refine details of their stories, explain and enrich their stories based on prior knowledge regarding scientific concepts; (ii) Unexpected variations appear in a great number of stories $(64,2 \%)$ as the mission to Mars is an unexpected and risky experience. Students create problems and try to think of possible solutions; (iii) students develop short stories (89.2\%) by managing to remove unnecessary elements to make the essence useful. (3) In the promotion subcategory: (i) Storytelling and articulation (100/\%) which addresses the issue of crafting and sharing compelling and interesting stories was successfully met in all digital stories and (ii) Naming (100\%) was again successfully met as all stories had a title and some of them subtitles dividing the stories in chapters. Synthesis is presented in some stories. Students go beyond the subject or the field by connecting different subject and professional domains that have to be considered and combined for the success of the mission. However, it seems that this point was difficult 
for students. Metaphorical thinking seems to be more difficult for students, but analogies like "the sound of taking-off and landing is like an earthquake" are considered successful for this age. Nonverbal, five-sense, and body thinking seem to be easier for students as they used photos of Mars, Earth and satellites, spacecrafts and space stations, or video simulations showing astronaut preparation. The transformation and promotion categories indicate that students expand and enrich their knowledge, by giving scientific explanations, making experiments, and acting like creative scientists. Almost all of the stories have creative titles, or exciting events, like a discussion with aliens, or the transformation of crews' hobbies on Mars.

As far as Creative attitudes are concerned, open-minded type is confirmed because of the collaboration with robots or "Martian people," but it appeared in few stories (see Appendix, Table 4). Creative attitudes specifically involve the open-minded, playful, emotional, and daydreaming attitudes that students expressed in their stories. They appeared in very high frequency (open-minded 96.4\%, playful $100 \%$, emotional $100 \%$, and daydreaming $87.5 \%$ ) as young students have a tendency to correlate the creative process of writing with their emotions. In the stories, students often created humorous scenes, or they expressed their emotions and goal-oriented thoughts influenced by the cultural factor. Playful type seems to be more common in stories, as students acted with humor. For example, the main crew wondered if they could have ice creams on Mars. The emotional factors also play an important role. Spacecraft pilots were more stressed than others because a small mistake could prove dangerous for their lives, or the crew seemed to be excited for the new mission, but anxious about their families and the success of the mission. The day-dreaming factor means sustaining unrealistic but goal-oriented thoughts. For example, students pretended to use an internet connection and their parents' laptops to solve a problem, or the crews put fences around the refuge on Mars to avoid attacks. Students appear to be optimistic about the growth of colonies on Mars (Fig. 5). As far as effective learning environments are concerned, students in all stories had to communicate in order to make decisions about their missions in Mars. They tried to decide which trained staff members would be more appropriate for their mission, what they had to do under unknown or unpredictable circumstances on Mars, or how they decided to change their lives dramatically, by participating in a mission to another planet. By comparing schools from different countries, we can also examine different cultural or social beliefs. Simulations and art-based activities are also obvious in students' stories, as students created models of Mars, or they wore augmented glass so as to see the Mars for a moment. Dialogic space is also important, as students negotiated with each other about the scenario of their stories, the parts of their stories, and the pictures or drawings that enriched their stories. Several students made experiments in their school laboratories in order to represent living conditions on Mars. Some schools tried to represent the lack of gravity or the high pressure and temperature on the surface of Mars. Some schools visited research centers or asked researchers about, for example, an astronaut's preparation and training, the living conditions on Mars, etc. We have noticed that when the students contacted professionals, they could represent their ideas in more enriched and creative ways. Moreover, most students wanted to write a whole scenario so as to narrate a story in an understandable way and communicate their ideas.

\section{Students' creativity evaluation model research tool}

Students' Creativity Evaluation Model Research tool consists of five main categories: (1) cognitive subjects (content/interdisciplinarity), (2) ICT tools, (3) representations/ visualizations of scientific ideas (e.g., videos, pictures, and drawings) regarding their content, (4) the socio-cultural factor and out-of-school activities, and (5) the socioemotional factor (see Appendix, Table 5). The first three categories are further analyzed considering the expected, original, and innovative aspects that students apply to their storytelling. This way we have a qualitative scaled measurement of the degree of creativity underlying the stories of Mars; on one side of the continuum, one finds the "expected" aspect, the low-level creativity, and on the other, the "innovative" aspect which indicates high-quality creative elements. The last two categories analyzed in this research tool derived from the analysis process and indicate students' need and tendency to emotionally connect with something familiar as they explore unknown territories.

In the first category "cognitive subjects," all stories examined $(100 \%)$ include the "expected" aspect, which denotes students' inherent need to ground their storytelling on their prior knowledge and beliefs. This means that students approach the development of stories in a scientific way by embedding scientific facts in fictitious conditions. Typical examples of the expected aspect are students' references to (1) scientific concepts/phenomena regarding Mars (color, size, unfavorable for human survival conditions, etc.), (2) the specific supplies they have to consider regarding fuel, food, (3) the necessary exploration equipment, (4) communication tools to keep in touch with the Earth, and (5) establishing accommodation facilities to enable their survival on Mars. However, the "original" aspect is tracked in 80.3\% of the stories in which students attempt small steps to move beyond the safe zone of prior knowledge and engage in making scientific hypotheses and predictions regarding unknown areas. For example, students comment on the reasons why they chose to colonize Mars instead of Venus based on scientific elements. They thoughtfully and 


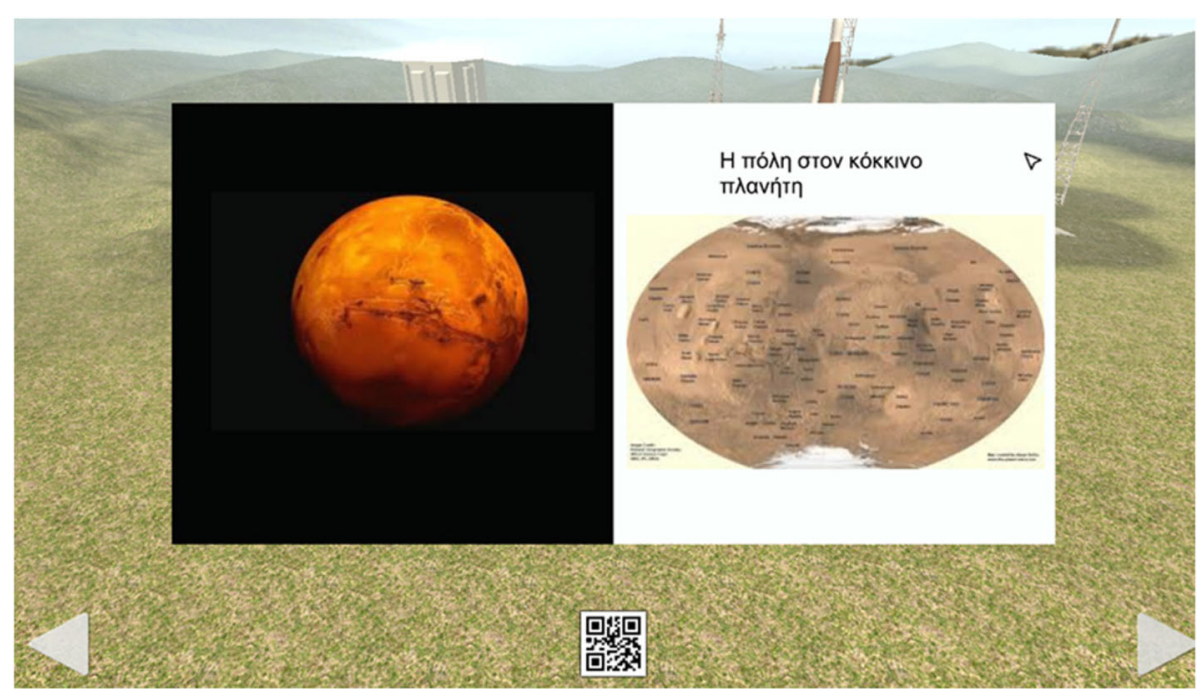

Fig. 5 An example of a student's story referring to a city on Mars

thoroughly designed their space suits to withstand the adverse conditions on Mars (e.g., white color to reflect heat). They even stress the need for suitable education and training that are required to ensure their survival on Mars (e.g., zero gravity conditions, building greenhouses, etc.). Finally, the "innovative" aspect is tracked in only $16 \%$ of the stories in which students feel comfortable enough to create and shape their own scientific reality about human habitation on Mars. In these stories, the young story-writers speculate and improvise on shaping the appropriate technical conditions to apply the cycle of water on Mars. They even reflect on the positive aspects of gravity absence in manipulating water streaming and solve the energy problem by encountering solar energy stones on Mars. Further, typical examples of the "innovative" aspect are imaginative ideas about the sleeping process which will be made possible by fastening the spacesuit belt.

In addition, all stories highlight in the "expected" factor the need to involve experts/scientists from different domains in order for the astronauts to be able to inhabit Mars. The typical professions that are mentioned are engineers, doctors, pilots, scientists, chemical engineers, and nuclear physicists. However, as we move from the "expected" aspect to the "innovative" aspect, 70\% of the stories mention a necessity for agriculturists, botany specialists, soldiers, and trainers, indicating their intentions to ensure and establish a permanent habitat for humans on Mars while $30 \%$ of the stories even make a reference to chefs, educators, history teachers, archaeologists, nutritionists, architects, and agronomists which implies the story-tellers' wish to solve the problem of permanent refuge of humans on the Red Planet. In other words, students applying the "innovative" aspect in their stories visualize Mars colonization and its sustainability and, thus, creatively attempt to ensure a historical tracking of human inhabitance on Mars.

The second category involves the quality of Information, Communication, Technology tools applied by the students in their digital stories. All stories are enriched with pictures and students' drawings of Mars depicting the planet's ground as well as drawings of a spaceship approaching Mars, visual items that address the "expected" aspect. In the "original" aspect, we have only $19.6 \%$ of the stories which have a video embedded depicting the spaceship's trip from Earth to Mars and/or vice versa and a very small percentage (3.5\%) for the "innovative" aspect. As in this category, we evaluate the degree of creative application of Information, Communication, Technology tools; we should note that in the "Stories of Tomorrow" project, the students were asked to write their stories in a high-tech digital platform that requires effort and time before its use. In order to set the accurate context for our analysis, we therefore need to clarify that students' application of further Information, Communication, Technology tools in their stories was not their priority. For this reason, we have low levels of creativity registered in this category, but we identify the need for further analysis of the samples of students' digital stories after they have spent a significant amount of time using the specific platform.

The third category "Representations/Visualizations of scientific ideas" requires further sampling at a later time; students need to create a second or third digital story in the platform. However, in the "expected" aspect all stories have ready-made pictures, the students' digitally created pictures, drawings of Mars depicting the planet's ground, planets, preparation phase of the mission, and the spaceship travelling from Earth to Mars and/or vice 
versa. This fact highlights a need for students to represent the content of their stories in an already familiar to them way that is why they use or create visual prompts that they have already seen either in their scientific research or in science fiction movies and/or documentaries. In the "original" aspect, we have only $16 \%$ of the stories which have a video embedded created by students, a simulation regarding the astronauts' preparation phase, simulation of safe landing on Mars, and a robot narrating the story. In the "original" aspect, we also classify some drawings that depict a greenhouse on Mars, the destruction of the Earth, and an explosion on Mars. Finally, in the "innovative" aspect, in $44.6 \%$ of the stories, there are highly creative drawings of refuges built on Mars, a visualization of an articulate inhabitance of Mars which shows the presence of water, a picture of scientific exploration of Martian stones (red circles applied in the photo similarly to a typical investigation), and even the use of legos to build a space vehicle. However, we should consider the difficulty of the representation/visualization category regarding the priorities given by the students, the amount of time required to visualize their ideas, the available tools, students' familiarity with the tools, and last but not least the difficulty to visualize something that they have never neither seen on experienced before in a way that is scientifically grounded.

The fourth category, "the socio-cultural factor and out-of-school activities," which derived from the analysis process is present in all stories $(100 \%)$ and indicates students' need to connect with past experiences, knowledge, and beliefs and transfer their understanding to an alternative content/different setting. Students make references to both micro- and macro-levels of the sociocultural factor in their stories: (1) micro-level regarding the professions/expertise necessary to ensure the sustainability of Mars colonization and human survival or the fact that students even acknowledge the necessity for historians that will track human civilization on Mars and (2) macro-level regarding students' explanation for the need for a mission to Mars in order for humans to face the imminent danger of Earth's destruction due to all the environmental and social issues. In other words, although students engaged in writing a story about the unknown, their creative ideas have their origins and their significance in the culture that created them. Students learn to communicate and negotiate by applying the socio-cultural elements. In addition, the feature of outof-school activities is present in all stories since students in the present activity highly engaged in possibility thinking and making conceptual connections from different subject domains (see theoretical framework).

In the fifth category, the "socio-emotional factor" is highly present in students' digital stories. All stories (100\%) make strong references to the emotions that the astronauts had before, during, and after the exploration on Mars. Each writing episode or scene is accompanied by references to the emotional state of the protagonists; the crew seemed to be excited about the mission to Mars; they felt sorry for leaving their families behind; they felt scared to face difficult situations such as running out of fuel, experiencing explosions, etc.; they were looking forward to travelling back to Earth, filled with awe when witnessing the magnificent view of space and realizing its uniqueness, self-satisfied, and proud of themselves for accomplishing their mission, etc. All these references indicate students' need to experience and feel the represented concept in order to be able to elaborate on their ideas and connect with the content they create.

\section{Expert's creativity evaluation model research tool}

There are both differences and similarities between expert and students' approach. The similarities are that students in their stories report elements from corresponding categories such as (a) scientific cognitive subjects or other, (b) technologies or other ICT tools, and (c) socioemotional aspects, but their representation and approach is different. For experts, story representation is guided by an abstraction of scientific domain such as astrobiology or astrochemistry (which are unknown to the students) and an up to bottom approach, while the opposite was true for students who acted with similar creativity.

\section{Cognitive subjects (content/interdisciplinarity/cross-linking)} The experts (scientists, researchers, and teachers) reported in their stories scientific content from astronomy (about Mars, the planets of the solar system, the exoplanets, etc.) or astrobiology (astrobiology is a branch of biology concerned with the origins, early evolution, distribution, and the future of life in the universe), or biochemistry (sometimes called biological chemistry, is the study of chemical processes within and relating to living organisms), or they referred to different scientific objectives such as (a) understand the formation and evolution of terrestrial planets through investigation of the interior structure and processes of Mars, (b) determine the present level of tectonic activity and meteorite impact rate on Mars, etc.

The experts reported in their stories scientific content from astrobiology about the habitability factors (water, chemical environment, energy for metabolism, conducive physical conditions), possibility of life on other planets, etc. Astrobiology makes use of molecular, biophysics, biochemistry, chemistry, astronomy, exoplanetology, and geology to investigate the possibility of life on other planets and help recognize biospheres that might be different from that on Earth.

The experts reported in their stories scientific and professional content from previous or future missions (Mars1 was the first spacecraft launched to Mars in 1962, but communication was lost while in route to Mars) (attend launch activities for NASA's insight mission, May 3-5, 
2018, at Vandenberg Air Force Base near Lompoc, California) (Mars 2020-the Mars 2020 rover is a Mars planetary rover mission by NASA with a planned launch in 2020). Experts intended to investigate Mars, its surface, geological processes, and history, including the assessment of its past habitability and potential for biosignature preservation within accessible geological materials.

The experts reported in their stories scientific, professional, and anthropological content about human colonization of Mars. Some of the main reasons for colonizing Mars include economic interests, long-term scientific research best carried out by humans as opposed to robotic probes, and sheer curiosity. A NASA report states that "applicable frontier technologies include robotics, machine intelligence, nanotechnology, synthetic biology, 3-D printing/additive manufacturing, and autonomy." These technologies combined with the vast natural resources should enable pre- and post-human arrival in situ resource utilization (ISRU) in NASA to greatly increase reliability and safety and reduce cost for human colonization of Mars. The team comprises of scientists and engineers from multiple disciplines and is a unique collaboration between countries and organizations around the world. The experts report artistic content from famous movies or from other disciplines (literature, etc.) in their stories. The Martian (film) is the first movie that attempts to be realistic and that is actually about human beings grappling with the problems of exploring Mars, as opposed to various horror films set on Mars.

As far as Information, Communication, Technology tools/Multimedia/Technologies are concerned, the experts used in their stories all of them (videos, interactive objects, maps, avatars, Mars Ascent Vehicle, Planetary Protection Technologies, robotics, machine intelligence, nanotechnology, synthetic biology, 3-D printing/additive manufacturing). Last but not least, socio-emotional aspects were also evident, as the experts use in their stories RRI aspects (gender equality, ethics, etc.). Students' emotional and psychological reactions become evident in their stories (" $\mathrm{Pm}$ part of the crew or not, Im excited to be part of the mission, I am saddened to get away from my family" etc.).

\section{Discussion}

According to the data analyzed, this research suggests that students' creative skills have to be researched in a deeper way, studying the internal mechanisms of creative thinking. Standardized tools help us measure creativity and further understand how students' mental representations work in order to produce a creative product scientifically acceptable has to be studied further. These findings with CCQ Tool can offer a better understanding of what the complex content of scientific creativity is, as we do not only take into consideration students' creative writing. We also examine how students use scientific data and how they try to combine them in an enriched environment, using multiple representational systems at the same time. This indicates higher cognitive skills, as students have to produce stories, that are scientifically correct and creative at the same time, and to represent their stories with different semiotic systems. At the same time, we have to mention that the analyzed stories are only a small sample of the stories produced by all participants, as the program is still in progress. This could be seen as a limitation to our study, as studying and analyzing all the stories can lead us to new categories of scientific creativity. However, this research is part of the pilot study, and the biggest sample is going to be researched in future studies. In future studies, the data are going to be represented by both qualitative and quantitative, statistical analysis, but at this phase of our research it is crucial to understand whether the suggested research tools can actually offer a better understanding of creativity. The data confirm that these tools can lead us to some conclusions about how creative skills are organized by the students, how they are enriched with scientific data, and how these skills can be better understood in a creative concept (the missions to Mars) which is not part of National Curricula.

\section{Conclusions}

Considering the innovative and creative theme of the mission to Mars, the majority of stories are characterized as creative. It is worth mentioning that almost all of the stories combined science to creative ways of thinking; therefore, students produced both authentic and scientifically correct stories, as they justified their choices in their stories with scientific explanations. In addition, almost all the stories presented principles of different subject domains and scientific fields, as students tried to represent their stories with different semiotic systems. Different subject domains, like astronomy, physics, engineering, mathematics, archaeology, anthropology, philosophy, and robotics, were enriched with artistic and literary elements, represented with digital tools. Students transformed their personal values and beliefs into stories, and therefore this creative procedure was influenced by social, cultural, and ethnographical characteristics. As a result, these stories are not only the final product of students' imagination, but they also represent students' internal cognitive mechanisms. Decoding the stories confirms that students have to use higher cognitive skills. The present study is also important as it is based on a qualitative analysis of the students' cognitive and creative skills, while we have also examined the internal procedures that students follow in order to represent the scientific notions in creating a scientific, authentic story. 


\section{Appendix}

Table 4 Data of the content analysis of the "Inbox to Newbox" research tool

Inbox

Newbox

Creative Attitudes

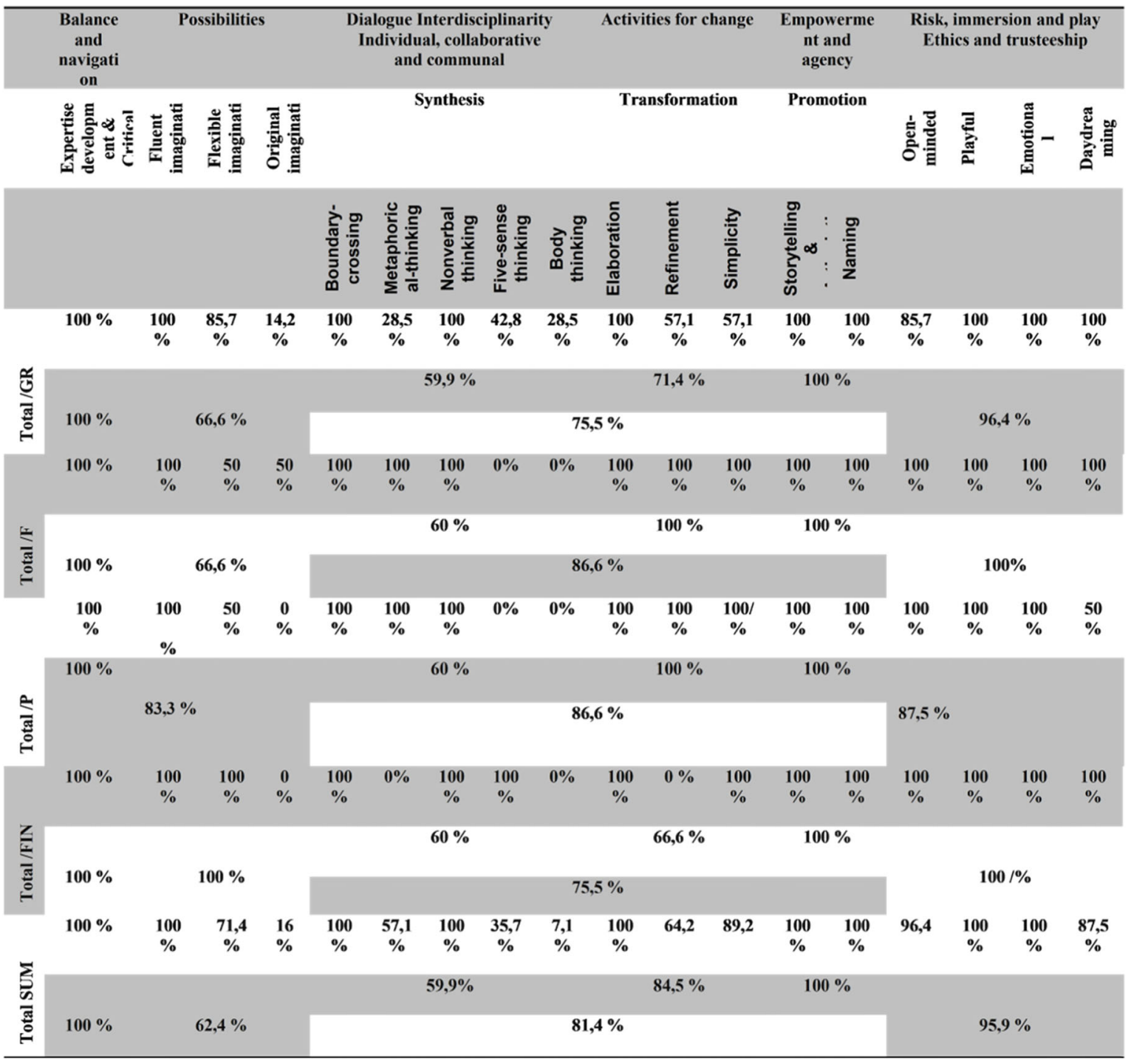


Table 5 Data from the content analysis of students' creativity evaluation model research

\begin{tabular}{|c|c|c|c|c|c|c|c|c|c|c|c|}
\hline & \multicolumn{2}{|c|}{$\begin{array}{l}\text { Cognitive subjects } \\
\text { (Content / } \\
\text { interdisciplinarity) }\end{array}$} & \multicolumn{4}{|c|}{ ICT tools } & \multicolumn{3}{|c|}{$\begin{array}{l}\text { Visualization } \\
\text { (manipulation of tools / context) }\end{array}$} & \multirow[t]{2}{*}{$\begin{array}{l}\text { Socio-cultural } \\
\text { factor }\end{array}$} & \multirow[t]{2}{*}{$\begin{array}{c}\text { Socio- } \\
\text { emotiona } \\
\text { factor }\end{array}$} \\
\hline & 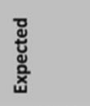 & 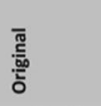 & 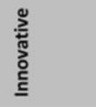 & 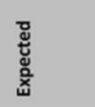 & 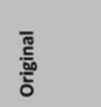 & 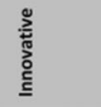 & 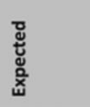 & 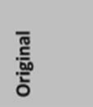 & 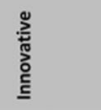 & & \\
\hline \multirow[t]{2}{*}{ Total GR } & $100 \%$ & $71,4 \%$ & $14,2 \%$ & $100 \%$ & $28,5 \%$ & $14,2 \%$ & $100 \%$ & $14,2 \%$ & $28,5 \%$ & $100 \%$ & $100 \%$ \\
\hline & & $61,8 \%$ & & & $47,5 \%$ & & & $47,5 \%$ & & $100 \%$ & $100 \%$ \\
\hline \multirow[t]{2}{*}{ Total F } & $100 \%$ & $100 \%$ & $50 \%$ & $100 \%$ & $50 \%$ & $0 \%$ & $100 \%$ & $50 \%$ & $50 \%$ & $100 \%$ & $100 \%$ \\
\hline & & $83,3 \%$ & & & $50 \%$ & & & $66,6 \%$ & & $100 \%$ & $100 \%$ \\
\hline \multirow[t]{2}{*}{ Total P } & $100 \%$ & $50 \%$ & $0 \%$ & $100 \%$ & $0 \%$ & $0 \%$ & $100 \%$ & $0 \%$ & $0 \%$ & $100 \%$ & $100 \%$ \\
\hline & & $50 \%$ & & & $33,3 \%$ & & & $33,3 \%$ & & $100 \%$ & $100 \%$ \\
\hline \multirow[t]{2}{*}{ Total FIN } & $100 \%$ & $100 \%$ & $0 \%$ & $100 \%$ & $0 \%$ & $0 \%$ & $100 \%$ & $0 \%$ & $100 \%$ & $100 \%$ & $100 \%$ \\
\hline & & $66,6 \%$ & & & $33,3 \%$ & & & $66,6 \%$ & & $100 \%$ & $100 \%$ \\
\hline \multirow{2}{*}{$\begin{array}{l}\text { Total } \\
\text { /SUM }\end{array}$} & $100 \%$ & $80,3 \%$ & $16 \%$ & $100 \%$ & $19,6 \%$ & $3,5 \%$ & $100 \%$ & $16 \%$ & $44,6 \%$ & $100 \%$ & $100 \%$ \\
\hline & & $65,4 \%$ & & & $41 \%$ & & & $53,5 \%$ & & $100 \%$ & $100 \%$ \\
\hline
\end{tabular}

\section{Abbreviations}

NKUA: National Kapodistrian University of Athens; SSCM: Scientific Structure Creativity Model; TTCT Figural Subscales: Torrance Test of Creative ThinkingFigural; CCQ tool: Creative, Cognitive, Qualitative Model for Creativity; ICT tools: Information and Communications Technology Tools

\section{Acknowledgements}

The research is based on the framework of the European Project CREATIONS (http://creations-project.eu/ CREATIONS (2015-2018), H2020-SEAC-2014-1 CSA, 66591) and the framework of The Stories of Tomorrow (STORIES) (http://www.storiesoftomorrow.eu/).

\section{Authors' contributions}

ZS and EG created the research tools for creativity, trying to research the initial mechanisms of students' creativity. They also designed the research protocol and the conceptual framework of creativity and wrote the manuscript collaboratively. ZS made substantial contributions to conception and design of the research and analyzed the data according to a mixdesigned research approach based on both qualitative and quantitative methods. EG participated in the research design, analyzed the data and drafted the manuscript. SS is the partner of STORIES Program. He specified the concept of STORIES and the context of the stories as a catalyst for the effective interaction between art and STEM disciplines. He also specified the program objectives, the vision of this research program, the collaboration to other partners and run the main procedures of the program. He provided the data for the main analysis. This research analysis offered the opportunity for a new synergy between two different partners from two European research programs. All authors read and approved the final manuscript.

\section{Funding}

The context of creativity has funded by the CREATIONS EU Program (http:// creations-project.eu/), in which 16 partners from ten European countries developed creative approaches based on Art for an engaging science classroom. The design of research tools and the analysis of data are funded as a part of the scientific research titled "Innovative Teaching Approaches" organized by the Faculty of Philosophy, Pedagogy and Psychology of the National Kapodistrian University of Athens. The context of Stories of Tomorrow (STORIES) is a research and development project funded by the European Commission, involving 15 project partners from 10 countries. This project has received funding from the European Union's Horizon 2020 research and innovation program under grant agreement no. 731872.

\section{Availability of data and materials}

The datasets used and/or analyzed during the current study are available from the corresponding author on reasonable request. Students' stories are available in research program platform (http://www.marsstories.eu/login), but as the program is still in progress, research participants' data will be available after the final phase of the program and will be obtained by emailing the corresponding author after their publication according to the principles of Open Access from European Union.

\section{Ethics approval and consent to participate}

Ethics approval and consent to participate adheres to the requirements and the main principles of all the educational agencies in each country-partner and the European Union.

\section{Competing interests}

The authors declare that they have no competing interests. There are not any financial or non-financial interests, as we are not influenced by any personal or financial relationship with other people or organizations. NKUA is a partner of CREATIONS EU Program and responsible for the theoretical research tool of creativity and the generation of the research thinking and the analysis of data. NKUA has expertise in the design of research tools based on qualitative research and design original research tools which based on both qualitative and quantitative approaches. The Research and Development Department Ellinogermaniki Agogi is a partner of CREATIONS EU Program and STORIES Program and responsible for the concept of digital storytelling. They also provide the main data for the analysis. The authors are partners of different European projects and the synergy between them is definite.

\section{Author details}

${ }^{1}$ School of Philosophy, Department of Educational Studies, National and Kapodistrian University of Athens (NKUA), University Campus, 15784 Ilissia, Athens, Greece. ${ }^{2}$ Research and Development Department, Ellinogermaniki Agogi, Dimitriou Panagea str., 15351 Pallini, Attica, Greece.

Received: 23 May 2019 Accepted: 5 May 2020

Published online: 16 June 2020

\section{References}

Aktamis, H., \& Ergin, Ö. (2008). The effect of scientific process skills education on students' scientific creativity, science attitudes and academic achievements. Asia-Pacific Forum on Science Learning and Teaching, 9(1), 1-21. 
Boase, C. (2008). Digital storytelling for reflection and engagement: A study of the uses and potential of digital storytelling. Retrieved February, 12, 2009. Boden, M. A. (2009). Computer models of creativity. Al Magazine, 30(3), 23-23. Braun, V., Clarke, V., Hayfield, N., \& Terry, G. (2019). Thematic analysis. In P. Liamputtong (Ed.), Handbook of research methods in health social sciences. Singapore: Springer

Chappell, K., \& Craft, A. (2011). Creative learning conversations: Producing living dialogic spaces. Educational Research, 53(3), 363-385.

Chappell, K., Hetherington, L., Ruck Keene, H., Slade, C., Cukorova, M. (2015). D2.1. The features of inquiry learning: Theory, research and practice. EU Project CREATIONS. CREATIONS (2015-2018), H2020-SEAC-2014-1 CSA, 665917.

Craft, A. (2005). Creativity in schools: Tensions and dilemmas. Abingdon: Routledge.

Foster, C., Wigner, A., Lande, M., \& Jordan, S. S. (2018). Learning from the parallel pathways of Makers to broaden pathways to engineering. International journal of STEM education, 5(1), 6

Ghassib, H. B. (2010). Where does creativity fit into a productivist industrial model of knowledge production. Gifted and Talented International, 25(1), 13-20 https://journal.world-gifted.org/.

Gobo, G. (2005). The renaissance of qualitative methods. In Forum Qualitative Sozialforschung/Forum: Qualitative social research, 6 (3).

Hewson, P., \& Lemberger, J. (2000). Status as the hallmark of conceptual learning. Improving science education: The contribution of research, 110-125.

Holmlund, T. D., Lesseig, K., \& Slavit, D. (2018). Making sense of "STEM education" in K-12 contexts. International journal of STEM education, 5(1), 32.

Hu, W., \& Adey, P. (2002). A scientific creativity test for secondary school students. International Journal of Science Education, 24, 389-403. https://doi.org/10. 1080/09500690110098912.

Kim, K. H. (2017). The Torrance Tests of Creative Thinking-Figural or Verbal: Which one should we use? Creativity. Theories-Research-Applications, 4(2), 302-321.

Krippendorff, K. (2018). Content analysis: An introduction to its methodology. Sage publications.

Li, Y., Wang, K., Xiao, Y., Jeffrey E. Froyd (2020). Research and trends in STEM education: A systematic review of journal publications. International Journal of STEM Education, 7 (11), https://doi.org/10.1186/s40594-020-00207-6.

Masemann, V. (2003). Culture and education. In R. Arnove \& C. Torres (Eds.), Comparative education: The dialectic of the global and the local (Second Edition) (pp. 115-132). New York: Rowman \& Littlefield Publishers, Inc..

Mingers, J., \& Willcocks, L. (2014). An integrative semiotic framework for information systems: The social, personal and material worlds. Information and Organization, 24(1), 48-70.

Mumford, M. D., Hester, K. S., \& Robledo, I. C. (2010). Scientific creativity: Idealism versus pragmatism. Gifted and talented international, 25(1), 59-64.

Perry, M., \& Medina, C. (2011). Embodiment and performance in pedagogy research: Investigating the possibility of the body in curriculum experience. Journal of Curriculum Theorizing, 27(3).

Samsudin, A., Setyadin, A. H., Suhendi, E., Chandra, D. T., \& Siahaan, P. (2018). Seventh grade students' scientific creativity test: A preliminary-study on earth science context. In IOP Conference Series: Materials science and engineering, 288 (1), IOP Publishing.

Sefertzi, E. (2000). INNOREGIO: Dissemination of innovation and knowledge management techniques. Report produced for the EC funded project, 1-19.

Sharma, A., \& Mahrshi, M. V. (2017). Construction and standardization of scientific creativity test. International Journal of Engineering Technology, Management and Applied Sciences. 5 (6), ISSN 2349-4476. www.ijetmas.com.

Shernoff, D. J., Sinha, S., Bressler, D. M., \& Ginsburg, L. (2017). Assessing teacher education and professional development needs for the implementation of integrated approaches to STEM education. International Journal of STEM Education, 4(1), 13

Simonton, D. K. (2012). Assessing scientific creativity: Conceptual analyses of assessment complexities. In National Research Council. (2014). Science of Science and Innovation Policy: Principal Investigators' Conference Summary. National Academies Press.

Smyrnaiou Z., Georgakopoulou E., Sotiriou M., Sotiriou S. (2018). Constructing scientific notions: Students' conceptual change. Co-Create! - Co-creation of curricula, tools and educational scenarios for building soft competences for personal development and employability, Science Centre AHHAA in Tartu, Estonia, 17-19 September 2018. https://rri-sis.wixsite.com/m-rrisis2018/cocreate2018

Smyrnaiou Z., Sotiriou, M. (2016). D2.3 Effective learning environments for inquiry learning and teaching, EU Project CREATIONS. CREATIONS (2015-2018), H2020-SEAC-2014-1 CSA, 665917.
Smyrnaiou Z., Sotiriou, M., Sotiriou, S. \& Georgakopoulou, E. (2017). Multisemiotic systems in STEMS: Embodied learning and analogical reasoning through a Grounded- Theory approach in theatrical performances. Journal of Research in STEM Education. WSEAS Transactions on Advances in Engineering Education,14, 99-112. ISSN / E-ISSN: 1790-1979 / 2224-3410, 14 2017, Art. \#12. http://www.wseas.org/multimedia/journals/education/2017/ a245810-083.pdf

Torrance, E. P. (1998). Torrance tests of creative thinking: Norms-technical manual: Figural (streamlined) forms A \& B. Scholastic Testing Service.

Toulmin, S. (1972). Human understanding, volume I: The collective use and evolution of concepts. Princeton.

Ward, T. B. (2007). Creative cognition as a window on creativity. Methods, 42(1), 28-37 https://doi.org/10.1016/j.ymeth.2006.12.002.

Yata, C., Ohtani, T., \& Isobe, M. (2020). Conceptual framework of STEM based on Japanese subject principles. International Journal of STEM Education, 7(1), 110 https://doi.org/10.1186/s40594-020-00205-8.

\section{Publisher's Note}

Springer Nature remains neutral with regard to jurisdictional claims in published maps and institutional affiliations.

\section{Submit your manuscript to a SpringerOpen ${ }^{\odot}$ journal and benefit from:}

- Convenient online submission

- Rigorous peer review

- Open access: articles freely available online

- High visibility within the field

- Retaining the copyright to your article

Submit your next manuscript at $\boldsymbol{\nabla}$ springeropen.com 